\title{
Phenotype and molecular diversity evaluation of some wild $2 n$ Solanum species (super series Rotata)
}

\author{
Dukagjin Zeka $^{1 *}$, Petr Sedlák ${ }^{1}$, Vladimíra Sedláková1 ${ }^{1}$ Kamal Sharma1 ${ }^{1}$ and Pavel Vej1 ${ }^{1}$
}

\begin{abstract}
New cultivars are result of the conservation and characterization of potato (Solanum) genetic resources in secondary germplasm banks. The objectives of this study were to assess phenotype diversity of 12 clones of 10 wild diploid potato species collection super series Rotata, and to determine their genetic diversity through simple sequence repeat (SSR) markers. Totally 63 alleles of 20 cpSSR loci were detected i.e. 3.15 alleles on average per one microsatellite locus. Alleles ranged from two to six per locus. The highest polymorphism was detected in the locus ntcp 9 and lowest were recorded having by two alleles in seven of loci. The average value of observed heterozygosity $\left(\mathrm{H}_{\mathrm{o}}\right)$ was 0.61 , whereas the mean of polymorphic information contents $(\mathrm{PIC})$ was 0.49 . Intergenic regions had highest variability $\left(\mathrm{H}_{\mathrm{igr}}=0.65\right)$ compare with introns $\left(\mathrm{H}_{\mathrm{in}}=0.54\right)$ and exons $\left(\mathrm{H}_{\mathrm{ex}}=0.45\right)$ of the chloroplast genome. Molecular analyses were complemented with tuft morphological measurements according to the descriptor list for the genus Solanum. SSR-based markers highlight a tendency to separate two groups of Rotata wild diploids and show the possibility of duplicities of wild potato genetic resources in the current $\mathrm{Czech}$ in vitro collection.
\end{abstract}

Key words: Heterozygozity, microsatellite, phenotype description, PIC.

\section{INTRODUCTION}

Central and South America are centers of origin and diversity of wild tuber-bearing Solanum species, and hence the primary sources of genes for disease and pest resistances lacking in modern cultivars (Bradshaw et al., 2006). The evolutionary diversity of the wild species and the comparatively narrow genetic basis of the cultivated potato make Solanum species unique materials for breeding (Carputo et al., 2013), which represents a tremendously diverse gene pool traditionally utilized as a source of various traits in potato breeding (Heřmanová et al., 2007).

Subsection Potatoe is divided into two superseries, Stellata Hawkes and Rotata Hawkes based on the corolla shape (Hawkes, 1990). Taxonomy of the genus Solanum based on the variability of morphological characters and phenology of plants had a long tradition (Correll, 1962; Okada and Clausen, 1983; Hawkes, 1990; Bradshaw and Mackay, 1994; Ochoa, 2004), but with the development of molecular analysis of nucleic acids, the polymorphism of different nuclear DNA regions i.e. mtDNA and cpDNA introns and non-coding intergenic spacers offers higher potential to clarify phylogeny of the genus

${ }^{1}$ Czech University of Life Sciences Prague, Faculty of Agrobiology, Food and Natural Resources, Kamýcká 129, Prague 6, Suchdol 165 21, Czech Republic. "Corresponding author (zeka@af.czu.cz).

Received: 29 May 2014.

Accepted: 4 February 2015.

doi: $10.4067 /$ S0718-58392015000200002
(Kocyan et al., 2007; Miz et al., 2008). Also molecular markers are particularly attractive while they provide a direct estimation of genetic diversity and can help in the selection of parents that guarantee a superior genetic combination (Bisognin and Douches, 2002; Carputo et al., 2013) what is necessary in ex situ systems of biodiversity maintaining.

Microsatellites polymorphism analyses were used to study of genetic diversity in numerous crop plant species including potato (Bryan et al., 1999; Zeka et al., 2014), sunflower (Wills and Burke, 2006) and pepper (Hanáček et al., 2009). In the light of molecular research are newly presumed existence of 100 wild and only four cultivated species (Spooner, 2009; Ovchinnikova et al., 2011). Studies of species boundaries in the wild potato and their progenitors serves to illustrate the need for a variety of morphological and molecular approaches to comprehensively address complex problems of species limits (Spooner, 2009).

The main aim of this study was to evaluate wild diploid Solanum super series Rotata genotypes/species diversity through comparing molecular and phenotype characterization and possibly find duplicities preserved in Czech Gene bank collections in vitro.

\section{MATERIALS AND METHODS}

\section{Plant material}

Twelve wild tuber-bearing diploid genotypes from random seedlings belonging to 10 Solanum species were used in this 
study. Wild diploid species of super series Rotata included: Solanum berthaultii Hawkes (EVIGEZ-00269), $S$. gourlayi Hawkes (EVIGEZ-00043 and EVIGEZ-00045), S. incamayoense K.A. Okada \& A.M. Clausen (EVIGEZ-00045), S. leptophyes Bitter (EVIGEZ-00048), S. microdontum Bitter (EVIGEZ-00049), S. mochiquense Ochoa (EVIGEZ-00050), S. sparsipilum (Bitter) Juz. \& Bukasov (EVIGEZ-00071), S. spegazzinii Bitter (EVIGEZ-00060), S. vernei Bitter \& Wittm. (EVIGEZ-00060 and EVIGEZ-00234), and S. verrucosum Schltdl. (EVIGEZ-00299). Biological material was provided by the in vitro gene bank at Potato Research Institute Havlíčkův Brod Ltd., Havlíčkův Brod, Czech Republic. All genotypes were maintained as in vitro culture at 1x MS medium (Murashige and Skoog, 1962) with $2 \%$ sucrose and $0.7 \%$ agar in cultivation plant growth chamber (MLR-15 SANYO Electric, Osaka, Japan) at illumination of $14500 \mathrm{lux}$ and photoperiod 16:8 h.

\section{DNA extraction, cpSSR genotyping and phenotype characterization}

Total genomic DNA was extracted from young leaves $(100 \mathrm{mg})$ of single plants using DNeasy Kit (Qiagen, Germantown, Maryland, USA) according the manufacturer's instructions. DNA samples were analyzed with 20 nuclear SSR primer pairs (Table 2) described previously by Bryan et al. (1999). PCRs were performed in a $12.5 \mu \mathrm{L}$ volume containing $10 \mathrm{ng}$ of total DNA, $1 \times$ buffer $\mathrm{KCl}, 1.5 \mathrm{mM} \mathrm{MgCl} 2,0.5$ units of Taq polymerase, $0.4 \mu \mathrm{M}$ forward and reverse primers, and $0.3 \mathrm{mM}$ dNTPs (Fermentas, Vilnius, Lithuania). The PCR was carried out using the following cycling profiles: preliminary denaturing for $3 \mathrm{~min}$ at $94^{\circ} \mathrm{C}$ was followed by 27 cycles consisting from $40 \mathrm{~s}$ denaturing at $94{ }^{\circ} \mathrm{C}, 40 \mathrm{~s}$ annealing at $60{ }^{\circ} \mathrm{C}$ and $40 \mathrm{~s}$ elongation at $72{ }^{\circ} \mathrm{C}$ and closed by one final extension $10 \mathrm{~min}$ at $72^{\circ} \mathrm{C}$. Length polymorphisms of amplicon were detected in one capillary electrophoresis ABI Prism 310 Genetic Analyzer (Applied Biosystems, Foster City, California, USA). Ladder GeneScan 600 LIZ size standard (Life Technologies, Carlsbad, California, USA) was used for amplicons size evaluation.

Morphological characters were evaluated using Plant Genetic Resources Documentation in the Czech Republic (EVIGEZ) descriptor list for the genus Solanum L. (Vidner et al., 1987). Totally 26 characters of tuft were evaluated (Table 1) in 2 yr evaluating period in field trial in experimental field of Czech University of Life Sciences Prague (CULS, 5007'37” N; 14²2’36” E; 276 m a.s.1.), Prague-Suchdol, Czech Republic.

\section{Statistical analyses}

Molecular diversity was calculated for each locus. The average observed heterozygosity per locus was calculated as $H=N / N-1\left(1-\sum p_{i}{ }^{2}\right)$, where $N$ is the number of samples and $p_{i}$ is the frequency of $i^{\text {th }}$ allele (Nei, 1987). Polymorphic Information Content (PIC) was calculated using PICcalc (Nagy et al., 2012). A binary matrix where polymorphic loci were scored as presence (1) and absence (0) of an allele was constructed and statistically processed using Unweighted Pair Group Method with Arithmetic Mean (UPGMA). Dissimilarity matrix was calculated by means of Jaccard's coefficient in 1000 replicate bootstrapping

Table 1. Characteristics used in the phenotype analyses of the Solanum wild species super series Rotata.

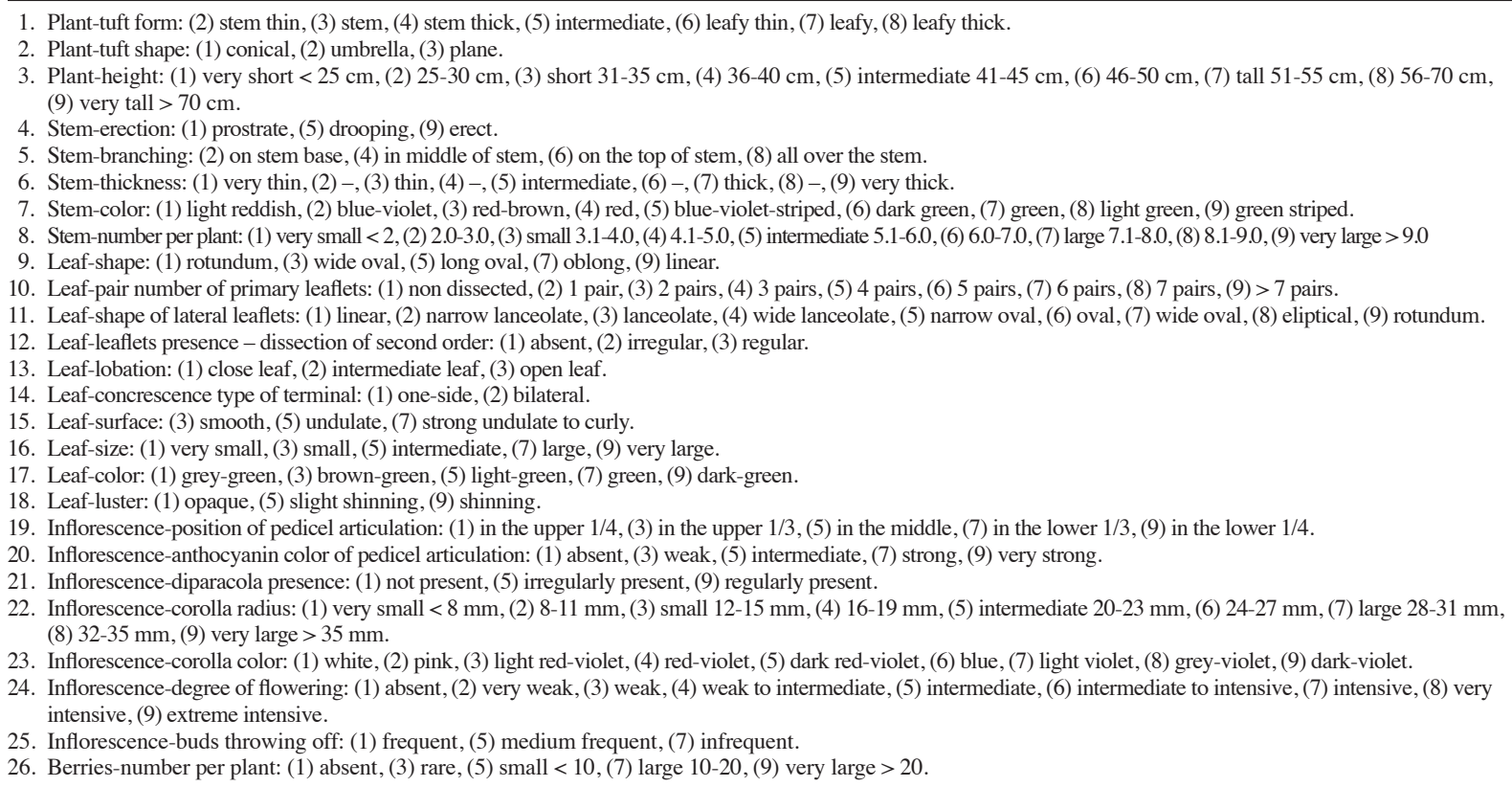


and graphically interpreted by means DARwin software v. 5.0 (Perrier and Jacquemoud-Collet, 2006).

Morphological dissimilarities between genotypes were analyzed by the Complete Linkage method. Cluster analysis was performed as Euclidean distance.

\section{RESULTS AND DISCUSSION}

A total of 63 SSR alleles were observed within the genotypes analyzed, highest polymorphism with a maximum of 6 alleles and observed average heterozygosity $\left(\mathrm{H}_{\mathrm{o}}\right)$ value 0.89 generated by the marker ntcp9 (Table 2). Despite this, couple of loci had by 2 alleles with range of $\mathrm{H}_{\mathrm{o}}=0.30$ (ntcp28) till $\mathrm{H}_{\mathrm{o}}=0.55$ (ntcp4). The size of

Table 2. Characteristics of microsatellite primers and results.

\begin{tabular}{llccccc}
\hline Locus & $\begin{array}{c}\text { Gene } \\
\text { location }\end{array}$ & $\begin{array}{c}\text { Expected } \\
\text { size }\end{array}$ & $\begin{array}{c}\text { Allele size } \\
\text { range (bp) } \\
\text { observed }\end{array}$ & $\begin{array}{c}\text { Nr of } \\
\text { alleles }\end{array}$ & $\begin{array}{c}\text { Average } \\
\text { heterozygosity }\end{array}$ & PIC \\
\hline ntcp3 & trnK in & 196 & $191-193$ & 3 & 0.62 & 0.48 \\
ntcp4 & trnK/rps 16 igr & 162 & $156-157$ & 2 & 0.55 & 0.38 \\
ntcp6 & rps16/trnQ igr & 176 & $167-171$ & 5 & 0.82 & 0.71 \\
ntcp7 & ORF98/trnS igr & 175 & $168-169$ & 2 & 0.48 & 0.35 \\
ntcp 8 & trnG in & 251 & $248-250$ & 3 & 0.68 & 0.55 \\
ntcp9 & trnG/trnR igr & 237 & $246-278$ & 6 & 0.89 & 0.79 \\
ntcp10 & atpF in & 120 & $110-112$ & 3 & 0.62 & 0.50 \\
ntcp12 & rps2/RF862 igr & 126 & $117-120$ & 3 & 0.56 & 0.55 \\
ntcp14 & psbM/trnD igr & 152 & $143-148$ & 5 & 0.85 & 0.74 \\
ntcp18 & psbC/trnS igr & 186 & $185-188$ & 4 & 0.71 & 0.60 \\
ntcp20 & ycf3 in & 122 & $112-114$ & 3 & 0.62 & 0.50 \\
ntcp23 & rps4/trnT igr & 122 & $108-110$ & 3 & 0.68 & 0.55 \\
ntcp24 & atpB ex & 157 & $148-149$ & 2 & 0.48 & 0.35 \\
ntcp27 & trnP/psaJ igr & 166 & $160-162$ & 3 & 0.71 & 0.58 \\
ntcp28 & rpl20/rps12 igr & 170 & $153-154$ & 2 & 0.30 & 0.24 \\
ntcp29 & clpP in & 157 & $150-151$ & 2 & 0.48 & 0.35 \\
ntcp30 & clpP in & 158 & $149-150$ & 2 & 0.41 & 0.30 \\
ntcp33 & rpoA ex & 149 & $145-146$ & 2 & 0.41 & 0.30 \\
ntcp39 & trnR/rrn5 igr & 156 & $149-151$ & 3 & 0.44 & 0.36 \\
ntcp40 & rp12/trnH igr & 163 & $263-287$ & 5 & 0.80 & 0.70 \\
Mean & & - & & 3.15 & 0.61 & 0.49 \\
\hline
\end{tabular}

${ }^{1}$ ex: exon, in: intron, igr: intergenic region.

PIC: Polymorphic information contents. amplicons ranged between 110 and 287 bp (Table 2). Mean value of observed average heterozygosity was 0.61 , whereas the mean of PIC was 0.49 . It is possible to compare $\mathrm{H}_{\mathrm{o}}$ values for SSRs in coding and non-coding regions. Intergenic regions had highest variability $\left(\mathrm{H}_{\mathrm{igr}}\right.$ $=0.65, \mathrm{n}=12)$ compare to introns $\left(\mathrm{H}_{\mathrm{in}}=0.54, \mathrm{n}=6\right)$ and exons $\left(\mathrm{H}_{\mathrm{ex}}=0.45, \mathrm{n}=2\right)$ of the chloroplast genome. Studies of wild potato species (Bryan et al., 1999; Zeka et al., 2014) and cultivars (Martyrosyan et al., 2007) by ntcp markers found that locus ntcp 9 showed the highest polymorphism. The high value of $\mathrm{H}_{\mathrm{o}}$ and PIC implies high level of dissimilarity within the studied species. A radial dissimilarity dendrogram on the basis of Jaccard's coefficient in the analyzed Solanum genotypes (Figure 1) based upon molecular analyses highlights a tendency to separate two differing groups of Rotata wild diploids - (i) S. berthaultii, S. mochiquense and two accessions of $S$. vernei, and (ii) two accessions of $S$. gourlai, S. incamayoense, S. leptophyes, S. microdontum, S. sparsipilum, S. spegazzinii and $S$. verrucosum. Nevertheless, any intraspecific polymorphism was not found between $S$. gourlai accessions and both of them resulted in one unique haplotype (Figure 1). The clustering patterns are in good agreement with results obtained from previous phylogenetic Solanum genus studies; in example Spooner (2009) found that most of these species did not form species-specific clades.

Phenotype clustering separated two groups also, but with different outline: (i) S. berthaultii, two genotypes $S$. gourlai, S. incamayoense, S. mochiquense, S. spegazzinii and two genotypes $S$. vernei, and (ii) S. leptophyes, $S$. microdontum, S. sparsipilum, and S. verrucosum (Figure 2). Morphological and molecular differences were observed between $S$. vernei accessions (EVIGEZ-00060

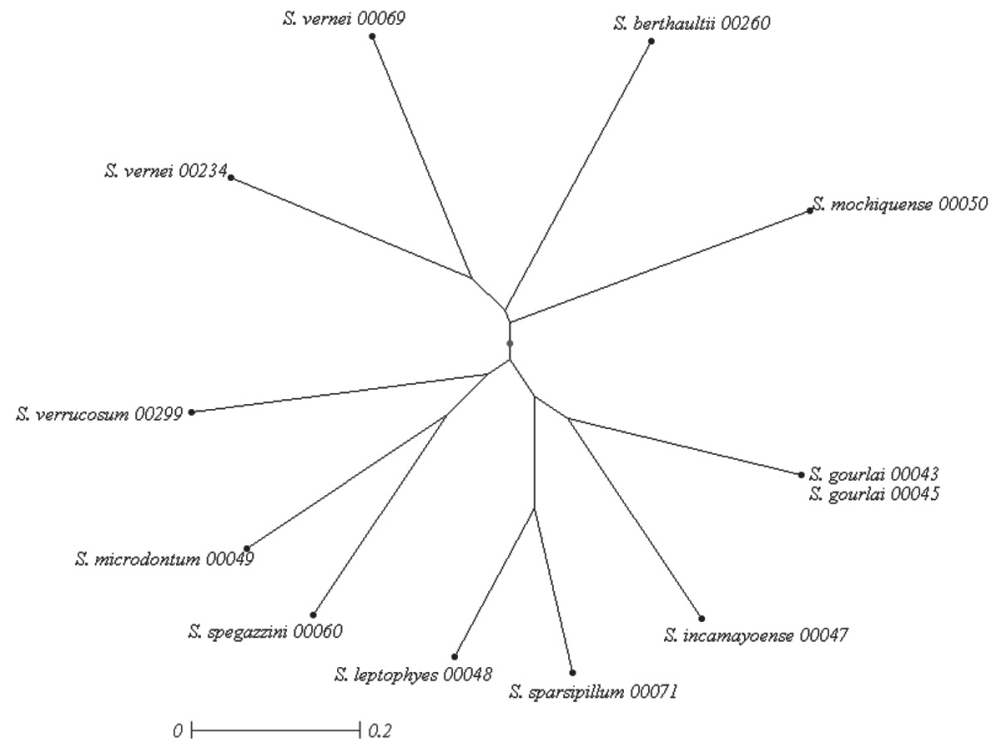

Figure 1. Jaccard's tree based on dissimilarity matrix of 12 Solanum genotypes examined with 20 microsatellite pair pairs. 


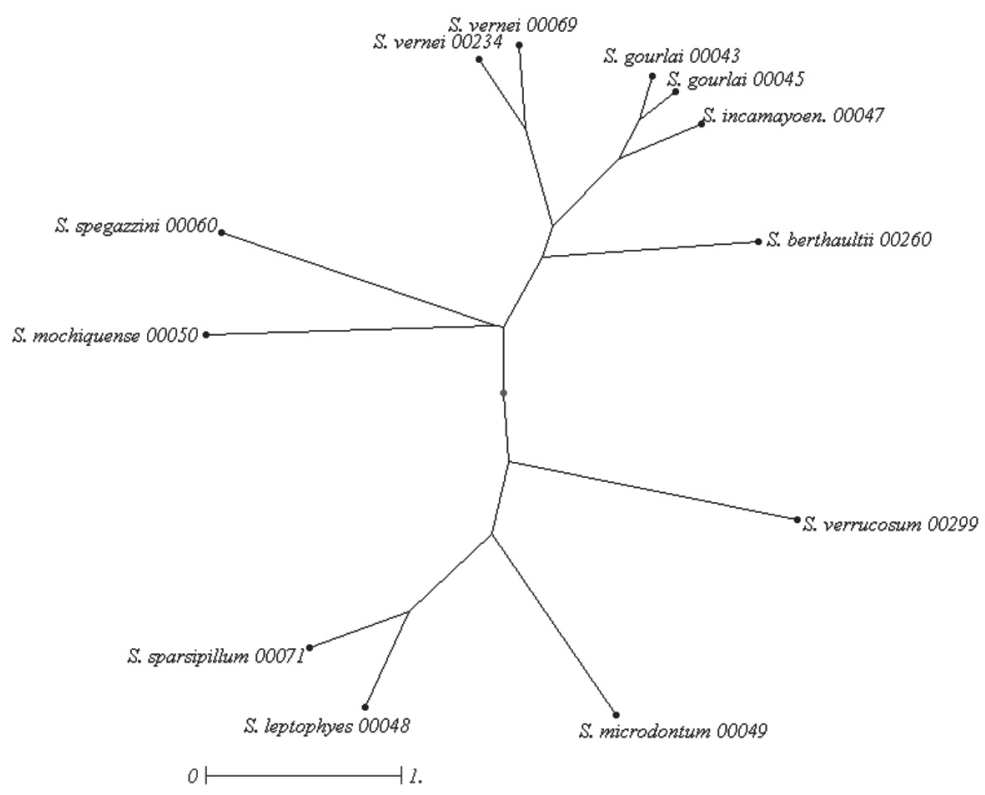

Figure 2. Dendrogram of Complete Linkage compressing tuft characteristics of 12 Solanum genotypes.

and EVIGEZ-00234). Molecular single-nucleotide polymorphism revealed in loci ntcp8, ntcp10, ntcp 28 , ntcp 29, and ntcp39; 2bp polymorphism occurred in loci $n t c p 14$ and ntcp27, whereas $30 \mathrm{bp}$ and 21 bp polymorphism was observed in loci $n t c p 9$ and $n t c p 40$, respectively. Moreover, $S$. vernei genotypes were distinct in seven of 26 traits of phenotype description (Table 3). Contrarily, both accessions of $S$. gourlai (EVIGEZ-00043 and EVIGEZ-00045) resulted in one SSR haplotype (Figure 1), and were slightly distinct only in stem color and leaf shape of lateral leaflets on phenotypic description (Table 3 and Figure 2). If we compare these two different observations and accept the hypothesis of conservativeness of cpDNA, we can postulate that accessions of $S$. vernei are not members of the same species. This is supported by distance of $S$. vernei clade from base line Figure 1 (less than 20\% similarity). On the contrary, the clustering of morphological descriptors confirms relatively high morphological similarity of both $S$. vernei accessions, but detailed view on crucial morphological description informs us about significant differences between them. This is also in good congruence to findings of RAPD analysis including both accessions done by Sedláková et al. (2009). With the respect to this finding we can responsibly notify that our results of morphological evaluation (Table 3) of wild $2 n$ Solanum species super series Rotata generally corresponded to the previous studies of tuft, stem, and leaves and inflorescence traits (Correll, 1962; Okada and Clausen, 1983; Ochoa, 2004).

SSR analysis classified $S$. gourlai and $S$.incamayoense accessions to the same cluster. This result was supported by phenotypic description also. Similarly S. leptophyes and $S$. sparsipilum were identically classified to common
Table 3. Solanum species phenotype traits evaluation results.

\begin{tabular}{|c|c|c|c|c|c|c|c|c|c|c|c|c|}
\hline Trait & 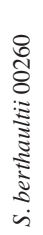 & 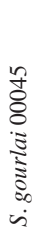 & 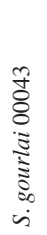 & 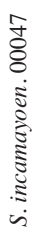 & 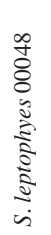 & 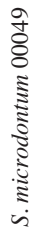 & 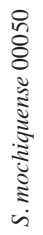 & 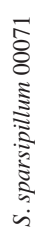 & 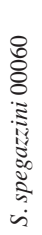 & 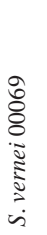 & 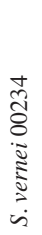 & 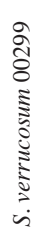 \\
\hline 1 Plant-tuft form & 7 & 5 & 5 & 5 & 5 & 7 & 8 & 3 & 2 & 8 & 8 & 3 \\
\hline 2 Plant-tuft shape & 1 & 3 & 3 & 3 & 1 & 1 & 1 & 1 & 1 & 3 & 3 & 2 \\
\hline 3 Plant-high & 5 & 2 & 2 & 2 & 3 & 7 & 2 & 4 & 2 & 5 & 5 & 1 \\
\hline 4 Stem-erection & 5 & 5 & 5 & 5 & 5 & 5 & 5 & 5 & 5 & 5 & 5 & 5 \\
\hline 5 Stem branching & 8 & 8 & 8 & 8 & 8 & 8 & 2 & 8 & 8 & 8 & 8 & 8 \\
\hline 6 Stem thickness & 6 & 4 & 4 & 4 & 6 & 8 & 6 & 6 & 4 & 7 & 7 & 3 \\
\hline 7 Stem color & 1 & 4 & 3 & 4 & 9 & 5 & 8 & 9 & 5 & 5 & 5 & 5 \\
\hline 8 Stem-number per plant & 1 & 1 & 1 & 1 & 4 & 7 & 1 & 8 & 2 & 4 & 3 & 9 \\
\hline 9 Leaf shape & 7 & 7 & 7 & 7 & 3 & 3 & 3 & 3 & 7 & 5 & 7 & 5 \\
\hline $\begin{array}{l}10 \text { Leaf pair number of } \\
\text { primary leaflets }\end{array}$ & 5 & 5 & 5 & 5 & 5 & 2 & 4 & 5 & 5 & 6 & 5 & 3 \\
\hline $\begin{array}{l}11 \text { Leaf shape of lateral } \\
\text { leaflets }\end{array}$ & 4 & 5 & 4 & 5 & 5 & 6 & 5 & 7 & 4 & 5 & 5 & 4 \\
\hline 12 Leaf leaflets presence & 2 & 2 & 2 & 2 & 2 & 2 & 3 & 3 & 3 & 3 & 3 & 2 \\
\hline 13 Leaf lobation & 1 & 2 & 2 & 2 & 2 & 3 & 3 & 3 & 3 & 1 & 2 & 2 \\
\hline $\begin{array}{l}14 \text { Leaf concrescence } \\
\text { type of terminal }\end{array}$ & 2 & 2 & 2 & 2 & 2 & 2 & 2 & 2 & 2 & 2 & 2 & 2 \\
\hline 15 Leaf surface & 5 & 5 & 5 & 5 & 5 & 5 & 7 & 5 & 3 & 7 & 5 & 3 \\
\hline 16 Leaf size & 5 & 3 & 3 & 3 & 5 & 5 & 5 & 5 & 3 & 7 & 7 & 3 \\
\hline 17 Leaf color & 1 & 7 & 7 & 7 & 9 & 7 & 5 & 9 & 1 & 7 & 7 & 7 \\
\hline 18 Leaf luster & 1 & 5 & 5 & 5 & 5 & 5 & 5 & 5 & 1 & 5 & 5 & 1 \\
\hline $\begin{array}{l}19 \text { Inflorescence position } \\
\text { of pedicel articulation }\end{array}$ & 3 & 5 & 3 & 5 & 5 & 5 & 7 & 5 & 1 & 5 & 7 & 7 \\
\hline $\begin{array}{l}20 \text { Inflorescence anthocyanin } \\
\text { color of pedicel articulation }\end{array}$ & & 7 & 7 & 7 & 3 & 3 & 1 & 3 & 5 & 7 & 7 & 9 \\
\hline $\begin{array}{l}21 \text { Inflorescence diparacola } \\
\text { presence }\end{array}$ & 1 & 1 & 1 & 1 & 1 & 1 & 1 & 1 & 1 & 1 & 1 & 1 \\
\hline $\begin{array}{l}22 \text { Inflorescence corolla } \\
\text { radius size }\end{array}$ & 8 & 7 & 7 & 7 & 7 & 7 & 7 & 7 & 4 & 7 & 7 & 5 \\
\hline $\begin{array}{l}23 \text { Inflorescence corolla } \\
\text { radius color }\end{array}$ & 8 & 9 & 9 & 9 & 9 & 1 & 1 & 9 & 1 & 7 & 7 & 9 \\
\hline $\begin{array}{l}24 \text { Inflorescence degree } \\
\text { of flowering }\end{array}$ & 8 & 6 & 6 & 6 & 8 & 8 & 6 & 8 & 3 & 7 & 5 & 5 \\
\hline $\begin{array}{l}25 \text { Inflorescence buds } \\
\text { throwing off }\end{array}$ & 7 & 7 & 7 & 7 & 7 & 7 & 7 & 7 & 7 & 7 & 7 & 7 \\
\hline 26 Berries number per plant & 1 & 5 & 5 & 1 & 7 & 5 & 1 & 5 & 3 & 1 & 1 & 7 \\
\hline
\end{tabular}


cluster on the basis of both data sets, molecular and morphological, respectively (Figures 1 and 2). Regarding to the other species within the studied collection can be considered as being able to encompass genetically different material since we detected variability of microsatellites and phenotype traits in evaluated genotypes/species. Similar results of phenotypic description (Ochoa, 2004) and molecular characterization (Bryan et al., 1999; Spooner, 2009) of these species were reported.

\section{CONCLUSIONS}

Molecular and morphologic approach of species boundaries, in this case super series Rotata, confirms complexity and fragility in wild potato species determination taxonomy, even some of examined species were characterized as close relatives either by phenotypic and molecular analyses. Microsatellites results show the diversity and possibility of duplicities in the current Czech in vitro collection of the wild potato genetic resources.

\section{ACKNOWLEDGEMENTS}

This study was supported by S grant 21360/1312/3192 of Ministry of Education, Youth and Sports of the Czech Republic and OP Education for Competitiveness for granting postdoctoral fellowship ESF/MEYS CZ.1.07/2.3.00/30.0040.

\section{LITERATURE CITED}

Bisognin, D.A., and D.S. Douches. 2002. Genetic diversity in diploid and tetraploid potato late blight resistant germplasm. HortScience 37:178-183.

Bradshaw, J.E., G.J. Bryan, and G. Ramsay. 2006. Genetic resources (including wild and cultivated Solanum species) and progress in their utilisation in potato breeding. Potato Research 49:49-65.

Bradshaw, J.E., and G.R. Mackay (eds.) 1994. Potato genetics. CAB International, Cambridge, UK.

Bryan, G.J., J. McNicoll, G. Ramsay, and R.C. Meyer. 1999. Polymorphic simple sequence repeat markers in chloroplast genomes of Solanaceous plants. Theoretical and Applied Genetics 99:859-867.

Carputo, D., D. Alioto, R. Aversano, R. Garramone, V. Miraglia, C. Villano, et al. 2013. Genetic diversity among potato species as revealed by phenotypic resistances and SSR markers. Plant Genetic Resources 11:131-139.

Correll, D.S. 1962. The potato and its wild relatives. Contributions from Texas Research Foundation: Botanical Studies 4. Renner Texas Research Foundation, Renner, Texas, USA.
Hanáček, P., T. Vyhnánek, M. Rohrer, J. Cieslarová, and H. Stavělíková. 2009. DNA polymorphism in genetic resources of red pepper using microsatellite markers. Horticultural Science (Prague) 36:127-132.

Hawkes, J.G. 1990. The potato, evolution, biodiversity, and genetic resources. Belhaven Press, London, UK.

Heřmanová, V., J. Bárta, and V. Čurn. 2007. Wild potato species: Characterization and biological potential for potato breeding. Czech Journal of Genetics and Plant Breeding 43:73-81.

Kocyan, A., L.B. Zhang, H. Schaefer, and S.S Renner. 2007. A multi-locus chloroplast phylogeny for the Cucurbitaceae and its implications for character evolution and classification. Molecular Phylogenetics and Evolution 44:553-577.

Martyrosyan, E.V., N.N. Ryzhova, and E.Z. Kochieva. 2007. Polymorphism of chloroplast microsatellite DNA loci in Russian potato cultivars. Russian Journal of Genetics 43:1578-1581.

Miz, R.B., L.A. Mentz, and T.T. Souza-Chies. 2008. Overview of the phylogenetic relationships of some southern Brazilian species from section Torva and related sections of "spiny Solanum" (Solanum subgenus Leptostemonum, Solanaceae). Genetica 132:143-158.

Murashige, T., and F. Skoog. 1962. A revised medium for rapid growth and bioassays with tobacco tissue cultures. Physiologia Plantarum 15:472-497.

Nagy, S., P. Poczai, I. Cernák, A.M. Gorji, G. Hegedüs, and J. Taller. 2012. PICcalc: an online program to calculate polymorphic information content for molecular genetic studies. Biochemical Genetics 50:670-672.

Nei, M. 1987. Molecular evolutionary genetics. Columbia University Press, New York, USA.

Ochoa, C.M. 2004. The potatoes of South America: Peru (Part I: The wild species). International Potato Center (CIP), Lima, Peru.

Okada, K.A., and A.M. Clausen. 1983. Solanum incamayoense: A new tuberous species of Argentina. American Potato Journal 60:433-439.

Ovchinnikova, A., E. Krylova, T. Gavrilenko, T. Smekalova, M. Zhuk, S. Knapp, et al. 2011. Taxonomy of cultivated potatoes (Solanum section Petota: Solanaceae). Botanical Journal of the Linnean Society 165:107-155.

Perrier, X., and J.P. Jacquemoud-Collet. 2006. DARwin software. Available at http://darwin.cirad.fr/ (accessed April 2014).

Sedláková, V., P. Sedlák, P. Vejl, J. Domkářová, J. Horáčková, and Z. Škodáček. 2009. Characterisation of selected diploid genetic resources of genus Solanum intended for somatic hybridization with potato dihaploids. Agriculture 55:17-25

Spooner, D.M. 2009. DNA barcoding will frequently fail in complicated groups: an example in wild potatoes. American Journal of Botany 96:1177-1189.

Vidner, J., K. Dobiáš, J. Konrád, P. Dědič, I. Bareš, and J. Sehnalová. 1987. Descriptor list genus Solanum L. Crop Research Institute (Výzkumný Ústav Rostlinné Výroby, V.V.I.), Prague, Czech Republic.

Wills, D.M., and J.M. Burke. 2006. Chloroplast DNA variation confirms a single origin of domesticated sunflower (Helianthus annuиs L.) Journal of Heredity 97:403-408.

Zeka, D., P. Sedlak, V. Sedlakova, J. Vasek, J. Domkarova, and P. Vej1. 2014. cpDNA SSR polymorphism in secondary germplasm of potato maintained in Czech gene bank. Pakistan Journal of Agricultural Sciences 51:745-750. 